\title{
THE IMPORTANCE OF EMERGENCY PREPAREDNESS AND BUSINESS CONTINUITY PLANNING FOR BUSINESS RESILIENCE: A LITERATURE REVIEW
}

\author{
THARSHANTH K. ${ }^{1}$, DAMITHA RAJINI ${ }^{2} \&$ THATSHAYINI P. 3
}

1,2,3 Department of Building Economics, University of Moratuwa, Sri Lanka

1Ktshanth1992@gmail.com, 2damee_uom@yahoo.com,3pthatsha@gmail.com

\begin{abstract}
All business activities are subjected to risks such as technology failure, natural disasters, utility disruption and terrorism, etc. These risks may be potential to generate a crisis, which if left uncontrolled can become a disaster. Even a small business interruption will result in the reduction of revenues, loss in customers or reduction in market share and ultimately, the survival of a business. Therefore, Emergency Preparedness (EP) and Business Continuity Planning (BCP) play an important role in business resilience providing the capability to adequately react to operational disruptions, while protecting safety and welfare of people. Though EP and BCP form important elements of good business management and service provision, as per the literature, EP and BCP have often been overlooked and sometimes even been ignored. Therefore, this paper presents the findings of a comprehensive literature review carried out on EP and BCP concepts to fill the above research gap. The finding will help the researchers working in EP and BCP practices to understand how these concepts have been developed, how they are practiced in the industry and their importance in business survival.
\end{abstract}

Keywords: Emergency Preparedness (EP), and Business Continuity Planning (BCP), Process, Business Resilience

\section{Introduction}

Ensuring the resilience of a business in any organisation is a must for the success of the organisation in this global market. "Business resilience is the ability of an organisation's business operations to rapidly adapt and respond to internal or external dynamic changes and continue operations with limited impact to the business (IBM Corporation, 2004). All organisations need to face the risks and changes in their business environment. Risks may result in crisis, which may turn to a disaster if proper attention is not paid (Davies \& Walters, 1998). Kash and Darling (1998)stated, 85\% of organisations acknowledge that crises within the organisations are inevitable. Even a small business interruption will threaten the survival of a company as it result in the reduction of income, loss in customer (Davies \& Walters, 1998). Risks which are very common in any organisations have a negative impact on the continuity of the business.

Maintaining a balance between business resilience and risks is very important in ensuring the success of the organisation. Risks are also created by disasters which may be either a manmade or natural disasters which subsequently result in loss of people, loss of infrastructure, loss of telecommunication to an organisation which may result in emergency situations which need to be controlled to ensure the continuity of the business operations. Emergency preparedness and business continuity planning have been widely recognised as the important tools to ensure the business resilience. Hence, this research presents findings of a comprehensive literature review on emergency preparedness and business continuity planning in ensuring the resilience of the business. The aim of this paper is to study the potential risks and emergency situations which may disturb the business continuity, the concept of EP, BCP, BCP processes and role of facilities manager in BCP. Therefore, initiated this research with literature survey and review based on books, journals, research papers, articles, previous research investigations and internet. This paper includes the in-depth analysis of the research findings derived from the literature study analysis which is used to achieve the research aim. Finally, this paper elaborates the conclusions about the research summarizing the total content of the research and further directions also suggested to carry on reaches in future.

\section{Literature Review}

\subsection{EMERGENCY PREPAREDNESS}

Emergency is an unpredicted occurrence which requires immediate action which comprises communities or individuals (Hiles, 2004). Preparedness in the context of emergency management can 
be defined as a "state of readiness to respond to a disaster, or any other type of emergency situation comprising the activities, programs, that exist before an emergency that are used to support and enhance response to an emergency or disaster" (Bullock, Haddow, \& Haddow, 2008). According to Newsom and Carrell (2001), "A disaster is an emergency considered severe enough by local government to warrant the response and dedication of resources beyond the normal scope of a single jurisdiction”.

The definition of disasters can be classified according to its scope ranging from biological to geographical and climatologically (Warren, 2010). Apart from this industrial and transport related accidents can also be included under disasters. On the other hand when we look in to the categorization of disasters broadly, disasters can be categorised as natural disasters and man-made disasters (Davies \& Walters, 1998). During recent years it is observable that many countries around the world experience an increase in natural disasters such as tsunamis, hurricanes, floods, mudslides and earthquakes (Mudalige, 2011). Manmade disasters include hazardous material spills, infrastructure failure, or bio-terrorism. According to Mudalige (2011), man-made disasters have badly influenced the economy, society and environment and have resulted in the loss of 64000 lives as well. In addition, Mudalige (2011) has highlighted that there has been 35 major disaster events with the economic loss of more than US $\$ 6$ billion in the last 10 years.

The environment of disasters is "characterized by change, uncertainty, and a sense of urgency in which communications and decision-making systems may break down and standard operating procedures may not apply" (Lewis, 1998). Recovering from a disaster suddenly without proper preparedness is an unachievable task. According to Moore \& Lakha (2006), in disaster situations humans revert to preprogramed responses rather than adapting to the situation. In order to overcome this measure such as good planning, which includes mitigation measures is very essential to avoid losses. According to the IFRC and Red Crescent Societies (2004), in the past ten years almost two billion people have been affected by disasters. Preventing a natural disaster is very difficult, measures such as good planning, which includes mitigation measures can help reduce or avoid losses. Organisations need to have a good emergency management for a better emergency preparedness. "Emergency management includes all-hazard which incorporates response, recovery, mitigation and preparedness which aims to reduce risk from civil natural, technological, biological and instrumental disruptions" (Mc Entire, 2004).

According to Wilson (2010) emergency management comprises of eight emergency management principles which highlights the inclusion of the population as an essential component to successful practices. Comprehensive and progressive are the principles which describe the inclusion of all hazards and impacts relevant to them and anticipating future disasters respectively are the first two principles of emergency management. Emergency management principles also include the risk analysis in assigning priorities and resources and it also highlights the importance of integration among all elements of a community. In addition, encouraging the trust among individuals and organisations, coordinating stakeholders towards a common purpose, innovative approach and the inclusion of person with special knowledge in the field also has been discussed in the emergency management principles (Wilson, 2010).

The aim of emergency management is to "protect communities by coordinating and integrating all activities necessary to build, sustain, and improve the capability to mitigate against, prepare for, respond to, and recover from threatened or actual natural disasters, acts of terrorism, or other manmade disasters" (Federal Emergency Management Agency, 2009). According to the American Red Cross (2008) preparedness is a cyclical process which includes actions such as risk and capabilities assessment, developing strategy and resource programme, exercising plan and schedule, training, taking corrective actions and the improvement of plans. Another way in which to view the concept of 
preparedness is by reviewing mitigation and preparedness which are generally considered to be distinct activities, however at some point it is difficult to distinguish between them. Mitigation means sustained action taken to reduce or eliminate long-term risk to people and property from hazards and their effects. Mitigation distinguishes actions that have a long-term impact from those that are more closely associated with preparedness for immediate response to short-term recovery of a specific event (Federal Emergency Management Agency, 2009).

Emergency preparedness includes the collection and analysis of intelligence and information, and development of policies and plans according to relevant laws, regulations to perform assigned missions and tasks with involvement of personnel who has certification to perform assigned tasks. In addition, importance of equipment and systems necessary for the task and proper standard training and exercising the plans and taking corrective actions among the deviations resulting in the plans are the activities included in the emergency preparedness (Bullock, Haddow, \& Haddow, 2008). More over emergency preparedness in an organisation can be improved by Optimizing staff performance in an emergency situation and by improving long term response management. Apart from this techniques to mitigate financial loses in time of crisis is also very essential in improvising the emergency preparedness.

The following table elaborate the various dimensions or the elements of preparedness of the organisation and its associated activities.

Table 1: Dimensions of Preparedness and Its Associated Activities

\begin{tabular}{|l|l|}
\hline $\begin{array}{l}\text { Dimensions of } \\
\text { Preparedness }\end{array}$ & Associated Activities \\
\hline Hazard Knowledge & $\begin{array}{l}\text { Conducting hazard, impact, and vulnerability assessments. } \\
\text { Using loss estimation software, scenarios, and census data. } \\
\text { Understanding potential impacts on facilities, structures, infrastructure } \\
\text { and populations. } \\
\text { Providing hazard information to diverse stakeholders. }\end{array}$ \\
\hline $\begin{array}{l}\text { Management, Direction } \\
\text { and Coordination }\end{array}$ & $\begin{array}{l}\text { Assigning responsibilities. } \\
\text { Developing a division of labor and a common vision of response-related } \\
\text { roles and responsibilities. }\end{array}$ \\
$\begin{array}{l}\text { Forming preparedness committees, networks. } \\
\text { Adopting required and recommended management procedures (e.g., } \\
\text { National Incident Management System). } \\
\text { Providing training experiences, conducting drills, educating the public. }\end{array}$ \\
\hline $\begin{array}{l}\text { Formal and Informal } \\
\text { Response Plans and }\end{array}$ & $\begin{array}{l}\text { Developing disaster plans, evacuation plans, memoranda of understanding, } \\
\text { mutual aid agreements, collaborative partnerships, resource sharing } \\
\text { agreements. } \\
\text { Participating in broader and more general planning arrangements (e.g., } \\
\text { neighborhood and community preparedness groups, Urban Area Security. } \\
\text { Initiative regional plans, industry-wide preparedness initiatives). }\end{array}$ \\
\hline \multirow{3}{*}{ Life Safety Protection } & $\begin{array}{l}\text { Acquiring equipment and supplies to support response activities; Ensuring } \\
\text { coping capacity. } \\
\text { Recruiting staff. } \\
\text { Identifying previously unrecognized resources. } \\
\text { Developing logistics capabilities. }\end{array}$ \\
\hline $\begin{array}{l}\text { Preparing family members, employees, others to take immediate action to } \\
\text { prevent death and injury, e.g., through evacuating, sheltering in place, } \\
\text { using "safe spaces" within structures, taking emergency actions to lessen }\end{array}$ \\
\hline
\end{tabular}




\begin{tabular}{|l|l|}
\hline & $\begin{array}{l}\text { disaster impacts on health and safety. } \\
\text { Containing secondary threats, e.g. fire following earthquakes. }\end{array}$ \\
\hline \multirow{3}{*}{ Property Protection } & Acting expediently to prevent loss or damage of property. \\
& Protecting inventories, securing critical records. \\
& Ensuring that critical functions can be maintained during disaster. \\
& Containing secondary threats. \\
\hline
\end{tabular}

Source: Sutton \& Tierney (2006)

\subsection{BUSINESS CONTINUITY PLANNING (BCP)}

Business continuity planning has been widely accepted by most organisations of all sizes as being essential strategic management tool (Goyal, 2004). There are two terms namely, Business Continuity Planning (BCP) and Business Continuity Management (BCM) which need to be described before moving broadly into the BCP concepts. Business continuity plan is the advance planning for the future losses and creating strategies to recover from them in case of an emergency or disaster. On the other hand BCM are the management disciplines, and processes to provide a framework for building organisational resilience ensuring the continuous operations of all business functions (Fournai, 1998). In this context it is also very necessary to distinguish the terms disaster recovery planning and the business continuity planning where Business Continuity Planning relates to ensure that an organisation can survive an event that causes interruption to normal business processes and Disaster Recovery Planning is the process that takes place during and after an organisational crisis to minimise business interruption and return the organisation as quickly as possible to a pre-crisis state (Moore \& Lakha, 2006).

The implementation of a continuity plan and restoring of business in the event of an emergency is depending on the successful interaction of various components and strength and effectiveness of a BCP can be decreased by its weakest component (Federal Financial Institution Examination Council, 2003). It was identified that BCPs and tested on a basis without considering the effectiveness of the plan have been established (Hearnden, 1995). The business continuity coordinator or team facilitates needs to identify risk and take actions to implement risk mitigation strategies across business areas. Internal and external factors of business environment will have negative impact on BCP (Federal Financial Institution Examination Council, 2003). Even though in organisations BCP have been established they largely focused on information technology but a fully integrated BCP was examined by Hearnden (1995) focusing on five areas including loss of buildings, loss of key personnel, loss of proprietary information, loss of telephone system and loss of corporate stationery. Creating a successful BCP is very essential but lack of understanding of critical issues regarding people at the board level leads to inefficient BCP (Alexander, 1994).

According to Pitt and Hinks (2001)critical aspects of business continuity planning are carrying out $\mathrm{BCP}$ enterprise wide basis, ensuring full business impact analysis and risk assessment, validating $\mathrm{BCP}$ through testing, updating $\mathrm{BCP}$ to respond changes and subjecting $\mathrm{BCP}$ to independent audit. Implementation of $\mathrm{BCP}$ includes phases such as project initiation, risk assessment, design and development of the BCP, creation of BCP, testing, practicing and updating (Heng, 1996). These are the phases of BCP which will make it efficient.

\section{1) Project initiation}

This is the phase of establishing business continuity planning objectives and the requirements of the plan with approval of the senior management (Goyal, 2004). In this stage the personnel responsible for BCP should inform the executive on the critical areas of the core company, and should also be able to relate these to the business-critical aspects of the business support functions affected collaterally by a disaster (Fournai, 1998). 
2) Risk assessment

In this phase impacts on business by nonspecific events are identified. Identification of critical functions and the prioritation too happen during this phase. Maximum allowable downtime for critical business processes, recovery point objectives and backlogged transactions, and the costs associated with downtime are also identified during the phase (Federal Financial Institution Examination Council, 2003).

3) Design and development of $\mathrm{BCP}$

This phase includes the main things that need to be addressed in the BCP such as emergency response procedures, communication procedure, restoration procedures and external support (Goyal, 2004).

4) Testing and revision of $\mathrm{BCP}$

Testing the BCP is an excellent way to assess the strengths and weaknesses of plan to gain an appreciation of the inherent safety factor in the operations for the formalisation of better internal communication and the scope to test the own company and resources (Paton, 1999).

5) Maintenance and updating

According to Pitt \& Goyal (2004) in this phase experiences due to the BCP practice and shortfalls documented are incorporated into plans while addressing issues such as BCP review criteria and objectives, schedules and programme of review and plan distribution and security.

After the implementation, it is essential to know the outcomes. According to Ramesh (2011) final outcome of BCP exercise will be a set of measures to prevent disasters, BCP operational to handle the situation and a plan which acts as a road map when disaster strikes. According to Lam (2002) changes that will take place in the future in business continuity planning are inclusion of business threat to the survival of business, inclusion of physical safety of employees, decentralization of business operations and the expansion to include the regional impacts. Apart from this, how the goals of business continuity planning can be quantified, and they are quantified in terms of recovery time objective, recovery point objective, performance degradation, risks involved in measures and the cost of implementation (Aacharya, Gastmans, \& Denier, 2011). More over Lam (2002)have addressed regarding the business continuity awareness too which includes identifying and manging the business continuity requirements, emphasising business continuity as one of the key concept, holding awareness workshops, and BCP review meetings.

BCP for recovering facilities should consider an alternative for location with relevant size and capacity and required amenities to recover critical business functions the plan should include logistical procedures for moving personnel to the recovery location, in addition to steps to obtain the materials (Federal Financial Institution Examination Council, 2003). Importance of business continuity planning in making a business resilient has also been included in the standards such as ISO 22301 (Societal Security - Business Continuity Management System -requirements), ISO 22313 (Societal Security - Business Continuity Management System -Guidance) and PAS 2015 (Framework for Health Services Resilience). In order to ensure the success of the organisation while ensuring the business resilience emergency preparedness and business continuity planning will enhance the stability of the organisations. The success of an organisation's emergency preparedness and business continuity management relies on the input and experience of its staff as they need understand the organisation, its processes and the environment in which it belongs (Hiles, 2004).

\section{Conclusions and Way Forward}

Recent disasters all around the world have made the organisations globally recognise the importance of emergency preparedness and business continuity planning. Emergency preparedness and business continuity planning contribute immensely to the success and stability of the organisation. The entire 
organisation in a stage would undergo risks, to mitigate them business continuity planning techniques and emergency preparedness techniques are the essential tools for the organisation. According to the literature reviewed emergency preparedness will help to react in emergency situations without getting panic and it is a process which helps to adapt to emergencies. On the other hand business continuity planning will help the organisation to prepare the continuity plan to ensure the proper operation of critical functions of the organisations. In the current context competition among organisations is very high and therefore organisations need to ensure their stability in the organisation to reduce future losses.

Business continuity techniques are essential strategic making tool which can be short term or long term depending on the policies of the organisation. Different researches about business continuity techniques include techniques to evaluate the critical functions comprising of suitable criteria relevant to them. Even though the concepts of emergency preparedness and business continuity plan among organisations has widely recognised after the terrorist attack in the United States of America, globally there is no clear picture about the concepts in Sri Lanka. Therefore the next step in this research is to find the current practices of emergency preparedness and business continuity planning in Sri Lanka and the parties involved in the process and to analyse the importance of emergency preparedness and business continuity planning.

And Facilities management covers a wide range of facility services and the management of which can contribute to the relative success or partial failure of an organisations business. Therefore, there could be another way to direct future research to study the involvement of Facilities Manager in BCP and EP Sri Lankan context.

\section{References}

Aacharya, R. P., Gastmans, C., \& Denier, Y. (2011, October 7). Emergency department triage: an ethical analysis. BMC emergency medicine, 11(1), p. 16. Doi: 10.1186/1471-227X-11-16.

Alexander, K. (1994). A strategy for Facilities management. Facilities, 12(11).

American Red Cross. (2008). The 2008 Disaster Relief Program Annual Review. United Stated of America: American Red Cross.

Bullock, J. A., Haddow, G. D., \& Haddow, K. S. (2008). Natural Hazaeds and Emergency Management. London: CRC Press. Davies, H., \& Walters, M. (1998, March). Do all cries have to become Disasters? Risk and risk management. Property

Management, 16(1).

Federal Emergency Management Agency. (2009, September 11). Retrieved March 13, 2010, from

http://www.femagov/plan/mit planning/index.sn/m

Federal Financial Institution Examination Council. (2003). Business Continuity Planning.

Fournai, A. (1998). Business Continuity Planning, Work Place.

Goyal, M. P. (2004). Business continuity planning as a facilities management tool. Facilities, 22(3/4).

Hearnden, K. (1995). Business Continuity Planning.

Heng, G. M. (1996). Developing a suitable business continuity planning methodology. Infprmation Management and Computer Security, 4(2).

Hiles, A. (2004). Business Continuity: Best Practice World class Business Continuity Management.

IBM Corporation. (2004). The next step forward for business Continuity. Business Reliance.

Kash, T. J., \& Darling, J. R. (1998). Cries Management: Prevention, diagnosis and intervention. Leadership \& Organization Development Journal, 19(4).

Lam, W. (2002, June 1). Continuity Planning. Ensuring Business Continuity, pp. 19-25.

Lewis, R. (1998). Management Issue in Emergengy Response.

Mc Entire, D. A. (2004). The Status of Emergency management theory, Issues, Barriers and Recommendatons for improved Schlorship.

Moore, T., \& Lakha, R. (2006). Tolley's hand book of Disaster Emergency management. Amsterdam.

Mudalige, J. (2011). Disaster management in Sri Lanka. Colombo: Disaster management in Sri Lanka.

Newsom, D. A., \& Carrell, B. J. (2001). Public Rlations Writing Form and Style.

Paton, D. (1999). Disaster Business Continiuity: Promoting Staff capability. Disaster prevention and Management, 8(2), 127133.

Pitt, M., \& Goyal, S. (2004). Business continuity planning as a facilities management tool. Facilities, 22(3-4), 87-99. Doi: $10.1108 / 02632770410527824$.

Pitt, M., \& Hinks, J. (2001). Barriers to the operation of the facilities management: property management interface.

Facilities, 19(7-8), 304-308. Doi: 10.1108/02632770110390784. 
Sutton, J., \& Tierney, K. (2006). Disaster preparedness: Concepts, guidance, and research. California: Fritz Institute. Warren, M. J. (2010). The facilities manager preparing for climate change related disaster. Facilities, 28(11/12).

Wilson, L. (2010, September). Evaluating Emergency Prepardness Alternatives at Higher Institutions. 